\title{
PRACTICAL ASPECTS IN TEACHING DYNAMIC AND STATIVE VERBS ${ }^{1}$
}

\author{
Tsvetalina Aneva ${ }^{2}$
}

\begin{abstract}
The present research focuses on the practical aspects of teaching dynamic and stative verbs and suggests some pedagogical implications that could help language teachers build up effective methods to improve learners' competence in studying these verbs. The study uses descriptive qualitative and quantitative analysis to analyse learners' most common errors and deviations in the usage of specific stative verbs. The findings show that errors frequently appear in the choice of defining verbs that can be used as stative and dynamic, depending on the context they appear in the groups of verbs of appearance; verbs, describing mental processes and verbs of senses. L1 interference and overgeneralisation are the two most common sources of errors. The findings outlined in the paper can make the comprehension of the linguistic realisations of dynamic and stative verbs easier to master.
\end{abstract}

Key words: dynamic, stative verbs, classification, teaching, error analysis

\section{Introduction}

Language teaching has always placed a great importance on the interrelation between grammar and meaning in the structure of language. One way in which this interconnection can be explained is through an analysis of the lexical units expressing activities and states.

Most English coursebooks and grammar books focus on some specific characteristics of verbs and the difference between active and stative verbs. They put an emphasis on rare occurrences in the progressive form of stative verbs as they represent a state which does not involve a notion of movement toward completion. These verbs are presented in contrast to active verbs, which are syntactically non-stative and which involve a certain activity by the subject. In most grammar books students are asked to complete the verb by using its simple or progressive form as some verbs expressing a state may occur in the progressive.

1. The compiling of this paper has been partially funded by the National Programme for Young Scholars and Post-Doctoral students

2. Lecturer in English, PhD Candidate, Department of English Studies, Shumen University, Bulgaria, e-mail: c.aneva@shu.bg, ORCID 0000-0002-1193-420X. 


\section{Ways of teaching dynamic and stative verbs}

The present research focuses on the practical aspects of teaching dynamic and stative verbs and suggests some pedagogical implications. The examples illustrating the grammatical realisations of the two types of verbs are taken from the Corpus of Contemporary American English (COCA), the British National Corpus (BNC) as well as from English coursebooks and grammar books.

When teaching English verbs, it becomes obvious that most students lack enough knowledge about dynamic and stative verbs. Moreover, they make mistakes when using them. When asked to define the form of the verbs students are hesitant to choose between the simple and the progressive form as in the following example:

\section{The flower smells / is smelling good.}

In sentence (1) the speaker reports on what is perceived, i.e. the subject is not a perceiver. To make it more easily comprehensible, students' attention can be drawn to the difference between the three groups of verbs as follows:

Group A (dynamic): $\quad$ listen, look, touch, etc.;

Group B (stative): $\quad$ understand, know, believe, own, etc.;

Group C (dynamic / stative): feel, smell, sound, taste, think, have, etc.

The present study touches upon some learners' errors in mastering stative verbs when developing writing and speaking skills and focuses on some deviations in the exact usage of specific stative verbs. Additionally, it provides suggestions about making English stative verbs easier to master.

\section{Previous research in the field}

Verbs in English can be classified as stative (state) and dynamic (also called “action” “active”, “non-stative”) verbs. Generally, stative verbs (such as understand, believe, trust) refer to existence, senses, appearance, feelings and emotions, mental processes, and possession.

In contrast, dynamic verbs (such as walk, drive, watch) are mainly used to describe an action or an activity process. However, there is a third group of verbs which refer to both states and actions (Group C). Since the difference between these types of verbs could be difficult to understand especially by students with lower command of English and sometimes could be even confusing, it is more reasonable to talk about stative meanings and dynamic meanings than just stative verbs and dynamic verbs.

Stative verbs refer to states or conditions. Michael Vince describes a state as a situation in which "something stays the same" (1998, p. 7). Examples are know, 
believe, or understand. These verbs can be used in simple and perfect tenses. However, they are not used in any progressive form. This makes these verbs a little more difficult for students, which means that practice is essential. The table below presents the six groups of stative verbs with examples:

\begin{tabular}{|l|l|}
\hline Existence & be, exist \\
\hline Senses & see, hear, taste, smell, sound \\
\hline Appearance & seem, appear, look \\
\hline $\begin{array}{l}\text { Feelings and } \\
\text { Emotions }\end{array}$ & $\begin{array}{l}\text { love, hate, like, dislike, fear, wish, want, adore, care, desire, } \\
\text { mind, appreciate (=value), need, doubt }\end{array}$ \\
\hline $\begin{array}{l}\text { Mental pro- } \\
\text { cesses }\end{array}$ & $\begin{array}{l}\text { know, believe, prefer, agree, feel (=think), realise, forget, remem- } \\
\text { ber, recognize, see (=understand), recall, mean, deserve, per- } \\
\text { ceive, understand, think (=have an opinion), suppose }\end{array}$ \\
\hline Possession & have, belong, own, posess, owe \\
\hline
\end{tabular}

\section{Practical aspects}

- Verbs of senses should be modified by adjectives. Consider the following examples:

2. Even from a distance, Ethan's pace looked quick.

2(a). *Even from a distance, Ethan's pace looked quickly. (wrong)

To native speakers of English, the impulse to pair verbs of perception with adjectives is instinctive; adverbs sound completely wrong in their place. However, foreign learners, who are constantly reminded that grammar rules in English require verbs to be modified by adverbs in most cases, find it difficult to pair perception verbs with adjectives.

\section{This soup tastes delicious.}

\section{3(a). *The soup tastes deliciously. (wrong)}

Using an adverb in sentence (3a), makes it sound as if the soup itself is capable of tasting. The difference is particularly striking with the adjective "good" (4) and its corresponding adverb, "well”(4a).

4. This fabric feels so good on the skin.

4(a). *This fabric feels so well on the skin.

The difference could be demonstrated if the perception verb feel is replaced with another verb. In this case the adverb well $(4 a)$ would sound perfectly reasonable.

4(b). This fabric drapes so well over my shoulders.

Jim Miller gives an interesting practical explanation pointing out that stative verbs "cannot be used to answer the question "What happened?" (2002, p. 143). The following examples clearly illustrate that: 
5 a. What happened? Susan went into the station and bought a ticket

$5 \mathrm{~b}$. What happened? *They believed his parents.

$5 \mathrm{c}$. What happened? *They were very happy.

The answer to the question in 5(a) contains the verbs went and bought, which are dynamic and describe actions. Believed in 5(b) and were in 5(c) both relate to states and are not dynamic but stative.

Stative verbs do not occur in WH cleft constructions. These consist of, for instance, What she did was + a clause. Example (5) is acceptable while 5(a) is not.

6. What she did was e-mail all her friends.

6(a). What she did was know this theory.

Stative verbs typically exclude adverbs such as enthusiastically and quickly.

7. He quickly knew his parent is not acceptable. On the other hand,

7(a). They were quickly very cold is only acceptable if the sentence bears the meaning 'they quickly became cold'.

Another characteristic of stative verbs is that this type of verbs is rarely used in the imperative as in the following examples:

8. *Belong!

8(a) Love me!

McArthur (2009) points out that (8) is not acceptable but example 8(a) is occasionally acceptable.

There are certain common constructions which can be used with either action or stative verbs. For axample, will and would for habits are never used with stative verbs. Consider the following examples:

9. *I would own a motorbike. (not acceptable as own is a stative verb).

9(a). During the holidays we would meet at the beach every morning. (acceptable as meet is a dynamic verb)

In (9) using the verb would is not acceptable as it is followed by the verb expressing a state own. In this case the only possible construction is used to +inf. or the Past Simple Tense.

This study uses descriptive qualitative analysis and quantitative analysis to answer the research questions. The corpus in this study contains statements containing errors by students, taking their first and second year at university. Observation, documentation and data reduction are used to select and analyse the most common errors. 


\section{Data analysis and key findings}

The types of errors made by students are divided into 6 groups: verbs of existence $(5.9 \%)$, verbs of senses $(17.6 \%)$, verbs of appearance $(17 \%)$, verbs of feelings and emotions (23.5\%), verbs describing mental processes $(23.5 \%)$ and verbs of posession (11.7\%).

The following table illustrates the errors made by students at the beginning stage of learning English in their activities.

\begin{tabular}{|l|l|l|l|}
\hline $\mathbf{N}$ & \multicolumn{1}{|c|}{$\begin{array}{c}\text { Classification of } \\
\text { errors }\end{array}$} & Total errors & \multicolumn{1}{|c|}{ Percentage of errors } \\
\hline 1 & Verbs of Senses & 3 & $17.6 \%$ \\
\hline 2 & Existence & 1 & $5.9 \%$ \\
\hline 3 & Appearance & 3 & $17.6 \%$ \\
\hline 4 & $\begin{array}{l}\text { Feelings and Emo- } \\
\text { tions }\end{array}$ & 4 & $23.5 \%$ \\
\hline 5 & Mental processes & 4 & $23.5 \%$ \\
\hline 6 & Possession & 2 & $11.7 \%$ \\
\hline & & 17 & $100 \%$ \\
\hline
\end{tabular}

Table 1. Errors of using stative verbs in written statements

The findings show that errors frequently appear in the choice of defining verbs that can be used as stative and dynamic, depending on the context they appear in the groups of verbs of appearance; verbs, describing mental processes and verbs of senses. These verbs require more practice as they seem to be the most challenging to learners as there is no strict grammar rule. Students need to consider each situation in detail. However, by paying careful attention, they can learn to use these verbs correctly, thus avoiding errors.

Table 2 presents 5 types of errors observed in the usage of stative verbs functioning as dynamic, depending on their meaning and learners' attention should be focused on the distinction between them.

\begin{tabular}{|l|c|c|l|}
\hline № & $\begin{array}{c}\text { Sentences } \\
\text { with errors }\end{array}$ & $\begin{array}{c}\text { Correct } \\
\text { sentences }\end{array}$ & \multicolumn{1}{c|}{ Types of error } \\
\hline 1. & 12 & 28 & Verbs with different meanings \\
\hline 2. & 23 & 17 & $\begin{array}{l}\text { Verbs which are used to talk about a short period } \\
\text { of time or describe something temporary }\end{array}$ \\
\hline 3. & 10 & 30 & Verbs which express an activity or process \\
\hline 4. & 8 & 32 & Verbs which express the beginning of something \\
\hline 5. & 2 & 38 & Verbs used to emphasise something \\
\hline
\end{tabular}

Table 2. Brief description of students' errors 
Examples of errors made by the students are as follows:

\section{Verbs with different meanings.}

Students make mistakes failing to notice the different meanings of the respective verbs. Consider the following examples:

10. She's having fun. (to have fun = to enjoy oneself)

10(a). She is having a party at her flat on Saturday. (to have a party $=$ to organize a party)

11. They've been seeing each other for a month. (to see $=$ to date)

11(a). I'm seeing two politicians for a meeting tomorrow. (to see $=$ to have an appointment with)

11(b). He is seeing his doctor next week (to see $=$ to visit, consult) $)^{3}$

\section{Verbs which are used to talk about a short period of time or describe something temporary as in:}

12. Diana is being very tired this evening. (to be is used as a dynamic verb expressing a temporary state)

12(a). Stop doing that, Bill! You're being very silly. (=You are behaving badly / you are acting badly at the moment.)

The analysis of the results shows that some students, included in the study, fail to notice that using the verb in the Simple Tense (12a) would change the meaning of the sentence completely as the simple form would describe part of Bill's character.

Another common mistake that needs to be analysed is the difference between using feel and look in the Progressive.

13. I am feeling the fabric.

13(a). She is feeling his forehead to check his temperature.

13(b). I feel good.

In (13) and 13(a) learners need to bear in mind that feel is used as a dynamic verb expressing a voluntary action in the meaning of touch. In contrast, using the verb in Simple form as in 13(b) expresses a mood.

14. He's looking awful these days.

3. For a complete semantic network of "see" cf. Aneva (2019, pp. 22-35). 
14(a). He looks good. ${ }^{4}$

In (14) learners' attention should be focused on using the progressive form to describe the person's temporary look compared to his normal appearance.

\section{Verbs which express an activity or process.}

15. My little daughter is smelling the flowers. (activity)

15(a). Why are you smelling the soup? (activity)

15(b). It smells awful.

16. I'm tasting the meal. (activity)

16(a). This sandwich tastes delicious (=it has a delicious flavour).

The verbs in the sentences (15), 15(a) and (16) specify that the perceiver is "focusing" on a specific object. The sentences indicate that the subject is performing the action. The examples put an emphasis on the fact that the verbs of senses when used in their progressive form describe a volitional process. On the other hand, in 15(b) and 16(a) the verbs smell and taste describe the person's awareness of the quality of what is smelled or tasted. Regarding smell, "the two types are based on the verbs smell (inhale an odour) and emit (smell). The active type involves an agent who is able to perceive smell and an object that has the property to emit that smell" (Nedelcheva, 2020, in print). As for taste, the opposition is between its two meanings trying out (a meal) and savour (having a particular flavour).

Another verb describing an activity in the analysis is think. Being accustomed to using the verb think in its stative meaning, namely believe, part of the students do not consider its use as a verb, describing a process.

17. I am thinking about going to Scotland. (process = I am considering )

17(a). He's probably thinking about his next holiday.

17(b). I think his car is fantastic. (opinion = I believe)

17(c). What do you think of him?

\section{Verbs which express the beginning of something}

18. We're gradually remembering people we know. (= We are slowly beginning / trying to remember)

4. For a comparative analysis of "look" and "see" cf. Nedelcheva (2019, pp. 7-21). 
Being used to the stative meaning and seeing the verb in its simple form, $20 \%$ of the students do not consider the fact that in this sentence the verb remember accompanied by the preceding adverb expresses the beginning of a process.

\section{Verbs used to emphasise something}

19. I'm loving it! = I'm (really) enjoying it. (emphasis)

The last example (not very common in British English) demonstrates only 2 errors made by the learners and is included in the study simply because learners often ask about the use of this verb in the advertising slogan of a well-known fast food chain.

This memorable catchphrase sounds grammatically incorrect (love is a stative verb so it should say "I love it"). However, using the verb love in the Progressive aspect as in "I'm loving it" in the meaning of enjoy makes this sentence acceptable, i.e. I'm enjoying my cheeseburger.

The analysis presented above shows the following sources of errors:

- The target group of students included in the study are at the beginning stage of learning English as a second language. L1 interference and its negative influence can be observed since at this stage students are not that familiar with the use of the target language and for that reason they use their previous experience when acquiring new grammar.

- Overgeneralisation is a result of a partial learning of the target language. As they have not mastered the language yet, learners tend to apply rules and stick to them failing to consider the specific context in which the verbs appear.

The research clearly shows the types of errors made by the learners, which is a source of information that can help teachers correct students' errors and improve the effectiveness of their teaching.

\section{Conclusion and implications}

The findings outlined in the paper can facilitate the comprehension of the linguistic realisations of dynamic and stative verbs in English. The theoretical aspect provides a brief, comprehensive classification of the types of verbs. The analysis shows the different meanings that the verbs express and the ways in which they change according to the specific context and the concepts associated with them. The elicitations from the present paper may contribute to:

- the analysis of the linguistic realisations of dynamic and stative verbs; 
- examining the various meanings and the kinds of processes involved when the verbs are used in different contexts in English;

- within the domain of Foreign Language Acquisition (FLA) the study will contribute to a better understanding of English verbs and their usage and will thus help language teachers build up effective methods to improve learners' competence in studying dynamic and stative verbs.

\section{References:}

Aneva, Ts. (2019). The semantic network of "see" (a corpus-based study). Studies in Linguistics, Culture and FLT, Vol. 7. Sofia: Asenevtsi, 22-35. https://doi. org/10.46687/SILC.2019.v07.002

Evans, V. (2014). FCE use of English 1. Newbury: Express Publishing.

Hewings, M. (2005). Advanced grammar in use. Cambridge: Cambridge University Press.

Hopkins, D., \& Cullen, P. (2007). Grammar for IELTS. Cambridge: Cambridge University Press.

McArthur, T. (1998). Stative verb. Oxford: Concise Oxford Companion to the English Language.

Miller, J. (2002). An introduction to English syntax. Edinburgh: Edinburgh University Press.

Nedelcheva, S. (2019). How seeing is different from looking? A cognitive perspective on verb-particle constructions with look and see. Studies in Linguistics, Culture and FLT, Vol. 7. Sofia: Asenevtsi, 7-21. https://doi. org/10.46687/SILC.2019.v07.001

Nedelcheva, S. (2020). Exploring smell from cognitive perspective in English and Bulgarian (a corpus study). Studies in Linguistics, Culture and FLT. Sofia: Asenevtsi, upcoming.

Norris, R. (2013). Ready for first. London: Macmillan Education.

Spasov, D. (1992). The verb in the structure of English. Sofia: St. Kliment Ohridski University Press.

Vince, M. (1998). Intermediate language practice. London: Macmillan Education.

Vince, M. (2003). First certificate language practice. Oxford: Macmillan Education.

Vince, M. (2008). MacMillan English Grammar in Context Advanced. Oxford: Macmillan Education.

Vince, M., \& French, A. (2017). IELTS language practice. London: Macmillan Education. 

Abbreviations:
BNC - British National Corpus
COCA - Corpus of Contemporary American English
FLA - Foreign Language Acquisition 